Brit. F. vener. Dis. (1973) 49, 464

\title{
Doxycycline (Vibramycin) in acute gonococcal urethritis
}

\author{
S. J. YAWALKAR, D. S. KUCHBAL, AND B. V. MARDHEKAR \\ From the G.T. Hospital, Bombay 1, and the Grant Medical College, Bombay 8, India
}

Because of the simplicity of administration and the lower risk of fatal allergic reactions, oral treatment of proven efficacy is replacing injections in some infectious diseases, including gonorrhoea. A single oral dose, given in the presence of the doctor, ensures that the proper treatment is taken and that the patient, being unaware of the name of the drug, cannot subsequently try self-treatment. We have previously used a single dose of $2 \mathrm{~g}$. oxytetracycline (Terramycin) to treat 65 patients with acute gonococcal urethritis and have obtained a cure rate of 93.8 per cent. (Yawalkar, Aurangabadkar, and Mardhekar, 1966).

Vibramycin (doxycycline) is prepared by the hydrogenation of methacycline and retains the general antibiotic properties of the tetracyclines. It is well tolerated, orally effective in relatively small doses with rapid and almost complete absorption, and, because of a long serum half-life of about $15 \mathrm{hrs,}$ produces an effective serum concentration for about $22 \mathrm{hrs}$.

Sylvestre and Gallai (1968a,b) reported a $94 \cdot 7$ per cent. cure rate in forty cases of acute gonococcal urethritis treated with a single oral dose of $300 \mathrm{mg}$. Vibramycin. Gallai and Sylvestre (1969) treated fifty young married couples having acute gonorrhoea with Vibramycin given orally in doses of $200 \mathrm{mg}$. twice daily for 2 consecutive days and reported a 100 per cent. cure rate. Frequent sexual intercourse was encouraged after clinical cure. On follow-up, 2 weeks after the treatment, no clinical signs of infection were observed and bacteriological examination was negative in all cases. Only a few minor sideeffects (e.g. nausea in two cases and diarrhoea in one) were observed. These reports prompted us to try Vibramycin in our cases of acute gonococcal urethritis.

\section{Material}

Eighty cases of gonorrhoea (79 men with acute gonococcal urethritis and one woman) were treated with Vibramycin and attended for follow-up at the Skin and V.D. Outpatient Department of the G. T. Hospital, Grant Medical College, Bombay. Their ages ranged from 13 to 51 yrs (Table I). There were 47 other patients who were treated, but they defaulted immediately and were excluded from assessment.

TABLE I Age distribution of patients

\begin{tabular}{ll}
\hline Age $(y r s)$ & No. of cases \\
\hline Under 20 & 14 \\
$20-30$ & 51 \\
$31-40$ & 10 \\
Above 40 & 5 \\
\hline Total & 80 \\
\hline
\end{tabular}

The average duration of the urethral discharge before treatment was 4 days, and the average incubation period $3 \frac{1}{2}$ days.

\section{Methods}

In all cases, the diagnosis was based on the demonstration of Gram-negative intracellular diplococci in urethral smears and positive cultures on chocolate agar medium. In the one female patient cervical tests were also done. Three different schedules of oral doses of Vibramycin were used:

(I) Twenty patients received $300 \mathrm{mg}$. Vibramycin in a single dose

(II) Twenty patients received $200 \mathrm{mg}$. in a single dose on the first day and the same dose on the next day.

In both of these groups the drug was taken in the morning after fasting over night.

(III) Forty patients received $400 \mathrm{mg}$. in a single dose. In twenty of these patients this dose was given after a large breakfast. The remaining twenty patients received the dose on an empty stomach. This comparison was made to study the effect of food on the incidence of side-effects.

All three groups of patients were re-examined on the 3rd and 7th days. They were considered to be clinically 
and bacteriologically cured when the following was noted:

(1) Complete disappearance of discharge

(2) Absence of the gonococcus in smears and cultures of urethral material and in the urinary deposit on the 3rd and 7 th days

(3) Absence of threads in the urine

(4) Negative smears and cultures of prostatic fluid on the 7 th day.

\section{Side-effects}

The patients tolerated Vibramycin only fairly well, but in no case were the side-effects severe enough to necessitate discontinuation of the treatment. Mild nausea and vomiting, giddiness, fever, and epigastric discomfort were encountered more frequently in the patients who took Vibramycin on an empty stomach.

Among the twenty patients in Group III who were given Vibramycin after food, there was a substantially lower incidence of side-effects; only two had mild nausea and vomiting (Table II).

Results (Table III)

(I) A single oral dose of $300 \mathrm{mg}$. Vibramycin resulted in cure in twelve out of twenty cases. The eight failures, who had positive smears and cultures, responded to oral Terramycin $250 \mathrm{mg}$. four times a day for 3 days.

(II) The double oral dose schedule of $200 \mathrm{mg}$. Vibramycin cured seventeen out of twenty cases. The three failures responded well to Erythrocin given orally in doses of $250 \mathrm{mg}$. four times a day for 3 days.

(III) The single oral dose of $400 \mathrm{mg}$. Vibramycin gave the best results and cured 38 out of forty cases, the

TABLE III Results of treatment with three different schedules

\begin{tabular}{|c|c|c|c|c|}
\hline Group & Dosage (mg.) & No. of cases & No. cured & $\begin{array}{l}\text { Cure rate } \\
\text { (per cent.) }\end{array}$ \\
\hline I & 300 single dose & 20 & 12 & 60 \\
\hline II & $\begin{array}{l}200 \text { first day } \\
200 \text { second day }\end{array}$ & 20 & 17 & 85 \\
\hline III & 400 single dose & 40 & 38 & 95 \\
\hline
\end{tabular}

response being more rapid than in the other two groups.

There were no instances of subsequent non-gonococcal urethritis in any of these three groups of patients.

\section{Discussion}

To achieve a good therapeutic result in cases of gonorrhoea, an initial high concentration of the drug in the serum is essential. Vibramycin, being rapidly absorbed, would seem to be a suitable drug. In a relatively small oral dose, it produces an effective serum concentration for about $22 \mathrm{hrs}$. Our results with a single dose of $300 \mathrm{mg}$. were not satisfactory, the cure rate being only 60 per cent. compared with the 94.7 per cent. reported by Sylvestre and Gallai (1968) and 94 per cent. by Lassus (1968). In this group the dose was not given after food and 40 per cent. of the patients experienced vomiting within an hour of taking the drug; this may have hampered its absorption and led to a low serum concentration.

Vibramycin given in two oral doses of $200 \mathrm{mg}$. on consecutive days produced a cure rate of 85 per cent. compared to 100 per cent. reported by Gallai and Sylvestre (1969) with doses of $200 \mathrm{mg}$. twice daily on 2 consecutive days.

Our best results were obtained with a single dose of $400 \mathrm{mg}$. which achieved a cure rate of 95 per cent. The frequency of vomiting was much lower when the drug was taken after food. $400 \mathrm{mg}$. is, therefore, the minimum effective dose of Vibramycin for acute gonorrhoea, but it should never be given on an empty stomach.

\section{Summary and conclusions}

Single oral doses of $300 \mathrm{mg}$. and $400 \mathrm{mg}$. Vibramycin resulted in cure in twelve out of twenty and 38 out of forty cases respectively, while $200 \mathrm{mg}$. given on two consecutive days resulted in cure in seventeen out of twenty cases.

Mild nausea and vomiting were encountered

TABLE II Incidence of side-effects

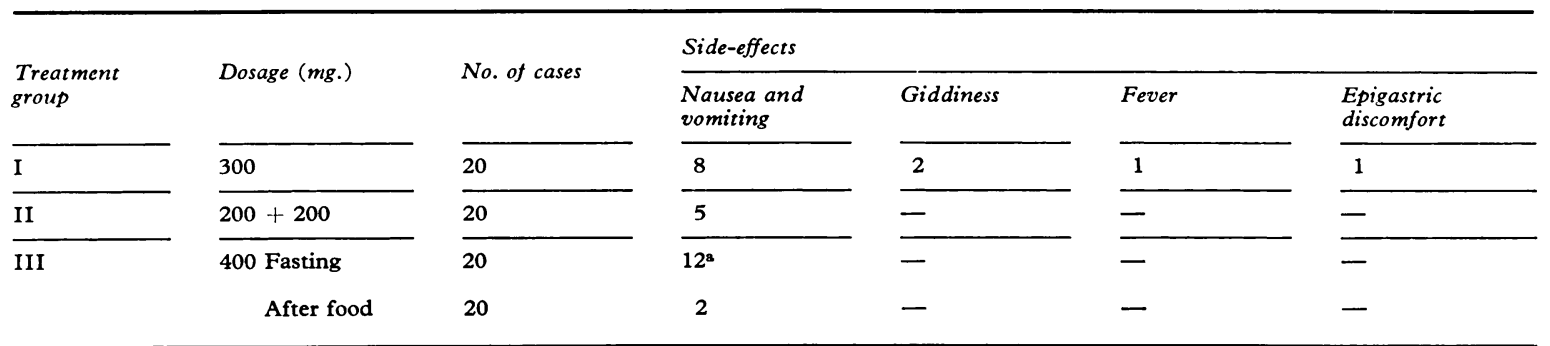

${ }^{a}$ Two of these complained of burning in the chest 
more frequently in patients taking the drug on an empty stomach. In no case were side-effects severe enough to necessitate discontinuation of the treatment. In view of its rapidity of action and good tolerance, a single oral dose of $400 \mathrm{mg}$. Vibramycin given after food is a useful method of treating gonorrhoea.

We are grateful to Prof. Dr. B. S. Kulkarni, F.R.C.P. (Edin.), Superintendent, G. T. Hospital, Bombay, for permission to conduct this trial and publish this report, and to Pfizer Ltd. for a liberal supply of Vibramycin and a grant to assist this study.

\section{References}

Gallai, Z., and Sylvestre, L. (1969) Paper read at VI International Congress of Chemotherapy, Tokyo

Lassus, A. (1968) Chemotherapy, 13, 366

SYLVESTRE, L., and GALlAI, Z. (1968a) Union méd. Canad., 97, 639 (1968b) Int. Z. klin. Pharmakol., 1, 401

YAWALKAR, S. J., AURANGABADKAR, J. W., and MARDHEKAR

B. V. (1966) Bombay Hosp. f., 8, 9 La doxycycline (Vibramycine) dans l'urétrite
gonococcique aigüe

SOMMAIRE

Des doses buccales uniques de $300 \mathrm{mg}$ et de $\mathbf{4 0 0} \mathrm{mg}$ de Vibramycine amenèrent la guérison, respectivement, de 12 cas sur 20 et de 38 cas sur 40 , cependant que $200 \mathrm{mg}$ donnés deux jours de suite guérissaient 17 cas sur 20 .

Des nausées légères et des vomissements furent recontrés plus fréquemment chez des malades ayant l'estomac vide lors de la prise du médicament. Aucun effet secondaire ne fut assez marqué pour obliger à suspendre le traitment. Du fait de sa rapidité d'action et de sa bonne tolérance, une dose buccale unique de $400 \mathrm{mg}$ de Vibramycine, donnée après le repas, est une méthode utile de traitement de la gonococcie. 